\title{
Promoting Collaboration in Health Care Teams through Interprofessional Education: A Simulation Case Study
}

\author{
Ozgur Ekmekci ${ }^{1}$ \\ ${ }^{1}$ School of Medicine and Health Sciences, The George Washington University, Washington DC, USA \\ Correspondence: Ozgur Ekmekci, School of Medicine and Health Sciences, Washington DC, 20037, USA. Tel: \\ 1-202-994-1623. E-mail: Ekmekci@gwu.edu
}

Received: January 25, 2013

Accepted: February 17, 2013

Online Published: February 20, 2013

doi:10.5430/ijhe.v2n1p78

URL: http://dx.doi.org/10.5430/ijhe.v2n1p78

\begin{abstract}
This simulation study explores how the integration of interprofessional components into health care curriculum may impact professional stereotyping and collaborative behavior in care delivery teams comprised of a physician, a registered nurse, a physician's assistant, a physical therapist, and a radiation therapist. As part of the agent-based modeling simulation, 500 students completed a curriculum with no IPE component and another 500 completed the same curriculum in which $25 \%$ of the courses being offered had IPE components embedded. The 500 students completing the non-IPE curriculum were asked to randomly form 100 health care delivery teams consisting of a member from each of the five professions examined in the study (i.e., MD, RN, PA, PT, and RT). The same was asked of the 500 students completing the IPE curriculum. The 100 teams in each group (constituting a total of 200 teams) were then asked to treat a patient over the course of a week. Findings indicate that the tendency for stereotyping was significantly lower $(\mathrm{p}<.001)$ for students attending curriculum containing IPE components, as compared to students attending curriculum without an IPE component. The individual and team mean scores for collaborative behavior - as represented by the number of links formed between team members throughout the seven-day period, during which the teams provided care to their patients - were significantly higher $(\mathrm{p}<.001)$.
\end{abstract}

Keywords: Interprofessional education, Collaboration, Professional stereotyping, Health care, Simulation

\section{Introduction}

The purpose of this paper is to use computer simulation to study how the integration of interprofessional components into health care curriculum impacts professional stereotyping and collaborative behavior in care delivery teams comprised of a physician, a registered nurse, a physician's assistant, a physical therapist, and a radiation therapist.

In the domain of health care, terms such as multidisciplinary, interdisciplinary, and multiprofessional have often been used synonymously since the 1960s to designate a context in which various professions and professionals are represented (Thistlethwaite, 2012). Especially over the last two decades, the World Health Organization (WHO) has been the main advocate for employing approaches that bring together individuals from different professions in the design of health care education, research, and practice (WHO, 1988; WHO, 2010). Largely due to these efforts, the term interprofessional has gained significant momentum in recent years, as a unifying term to define collaboration between individuals from different health care professions.

In this project, we focus on collaboration that is specifically grounded in interprofessional education (IPE). The most widely accepted definition (Barr, 2002; Thistlethwaite and Moran, 2010) of IPE is "all learning in academic and work based settings before and after qualification" through which "two or more professions learn with, from and about each other to improve collaboration and the quality of care" (CAIPE, 2012). Within that description, we further delimit our interest in IPE that takes place in an academic setting prior to qualification.

In a recent review of IPE literature (Thistlethwaite, 2012), forming a research agenda around health care curriculum has been deemed critical, as the effective development of IPE rests on our ability to "identify approaches for effectively graduating students with developed interprofessional capabilities" and to "review existing IPE programs for what has been learned and for what can be adapted to existing and new IPE initiatives" (p. 65). Achieving this level of awareness is imperative if health care students are to truly understand professional boundaries, reflect critically on their relationship with other members of a health care delivery team, and become aware of stereotypes that reside in self and in others. 
Lewitt, Ehrenborg, Scheja, and Brauner (2010) indicate that "understanding of each other's professional roles, enhanced personal professional confidence, preparation for interactions, communication and teamwork in their future professional lives" (p.60) are some of the key benefits with which health care students walk away from an IPE experience. Stereotyping - which is basically the preconceived set of beliefs as to where other professions belong within a particular hierarchy - has been identified as a major obstacle to effective learning and collaborative practice (Cooke, Chew-Graham, Boggis, and Wakefield, 2003). Therefore, designing IPE experiences for health care professionals, which allow participants to "balance the competing tensions of valuing one's own professional role, while developing more collaborative ways of practicing" is critical (Sargeant, 2009, p. 181) in terms of reducing stereotypes among team members from different professions and allowing them to see each other as more "caring" and "subservient" (Jacobsen and Lindqvist, 2009, p. 248).

Through their formal education, health care professionals need to be adequately prepared to master situations in which they shed their professional stereotypes and treat patients as part of an interprofessional team (Fernandez, Parker, Kalus et al., 2007). This is an essential ingredient for collaborative team work, since studies have indicated that health care students remain under the influence of the stereotypes they have developed during their training and tend to view their own profession in a more favorable light, as compared to others (Jacobsen and Lindqvist, 2009). Furthermore, when working as part of an interprofessional team, health care professionals must integrate shared learning into their actions (Cooper, Dewe, and O'Driscoll, 2001). After all, research investigating the benefits of IPE suggests that health professionals- through experiences involving IPE - may demonstrate more collaborative behavior that leads to higher satisfaction and productivity (Howell, 2009; Ruebling, Lavin et al., 2000) as well as lower morbidity rates for patients, fewer hospitalizations, and decreased costs (Ducanis and Golin, 1979; Gariola, 1997; Horbar, Carpenter, Buzas et al., 2004; Wager, Wickam, Glaser et al., 2005). A review of IPE literature reveals that the main push for more IPE is grounded in an ever-increasing volume of calls to institute formal learning opportunities for health care professionals that will enable participating individuals to acquire collaborative skills and leadership qualities that are much needed in today's complex global health care environment (Abu-Rish et al., 2012).

\section{Method}

Agent-based Modeling (ABM) was used in this study, as the method allows building computer models that enable social scientists to investigate complex social behavior using experiments, by simulating the social reality in which human interactions take place (Gilbert, 2008). The method has been used to study various social phenomena, such as racial segregation (Schelling, 1971), political opinion formation (Deffuant, 2006), consumer purchasing habits (Janssen and Jager, 1999), and formation of industrial networks (Gilbert, Pyka, and Ahrweiler, 2001). The ability to control social variables in an experimental environment also makes $\mathrm{ABM}$ a popular approach for social scientists investigating learning and collaboration that takes place over social networks (Gilbert et al., 2006).

The simulation used in this study involved 1000 health care students, namely: 200 attending the MD (medical doctor) program; 200 attending the RN (registered nurse) program; 200 attending the PA (physician assistant); 200 attending the PT (physical therapy) program; and 200 attending the RT (radiation therapy) program of a university. In the simulation, coded using the NetLogo language (Wilensky, 1999), half of the students (i.e., 500) completed a curriculum with no IPE component and the other half completed the same curriculum in which $25 \%$ of the courses being offered had IPE components embedded. Upon completion of their curriculum, the mean scores representing tendency for stereotyping were captured for all 1000 students completing the IPE and Non-IPE curricula.

The 500 students completing the non-IPE curriculum were asked to randomly form 100 health care delivery teams consisting of a member from each of the five professions examined in the study (i.e., MD, RN, PA, PT, and RT). The same was asked of the 500 students completing the IPE curriculum. The 100 teams in each group (constituting a total of 200 teams) were then asked to treat a patient over the course of a week. Sociograms - which are visual representations of networks, where nodes on the network depict individuals and line segments connecting the individuals depict the relationships that are being studied (Foster, Rapoport, \& Orwant, 1963) - produced in Netlogo (Wilensky, 1999) were used to plot the collaborative interactions that took place amongst members of each team over the seven-day period (Mehra, Smith, Dixon, and Robertson, 2006).

Figure 1 depicts how teams were structured in the simulation. The probability for collaborative behavior on any given day- between any two members of the team - was defined as:

$$
p(\text { collaboration })=0.5 *(1-p(\text { stereotyping }))
$$


where the even odds of collaboration (i.e., $50 \% / 50 \%$ ) were further delineated by the probability of individuals' tendency for stereotyping. All stereotyping and all collaborative behavior during the simulation runs were based on random probabilities generated by Netlogo (Wilensky, 1999).

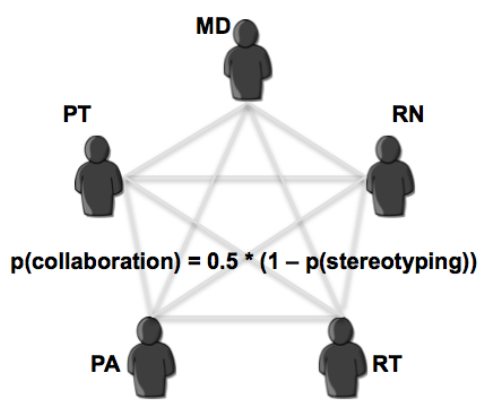

Figure 1. Probability of Collaboration between Team Members

Both individual and group data was captured for collaborative behavior (represented by the number of links forming between team members) throughout the seven-day period. The stereotyping and collaborative behavior for all 200 teams (100 IPE and 100 non-IPE teams) were then analyzed by running t-tests (using SPSS software) to determine statistically significant differences between the two groups' mean scores.

The generalizability of the findings of this study will be limited, namely due to the fact that this is an experimental design that greatly simplifies a very complex set of team dynamics. Without further research, it would be difficult to suggest that the findings of this study will apply for all real life cases involving IPE and teamwork. In particular, it should be noted that it is very difficult to isolate and observe the effects IPE components in health care, the way it has been done in this simulation study. Furthermore, it should be noted that there are likely other individual, team, and environmental factors that will interact with, moderate, cancel out, or distort the effect of the variables investigated in this study.

\section{Results}

Findings indicate that the tendency for stereotyping was significantly lower $(\mathrm{p}<.001)$ for students attending curriculum containing IPE components, as compared to students attending curriculum without an IPE component. The team mean scores and the result of the t-test for tendency for stereotyping between the IPE and Non-IPE teams are summarized in Table 1.

Table 1. T-test between IPE and Non-IPE Teams - Tendency for Stereotyping

\begin{tabular}{|c|c|c|c|c|}
\hline & IPE & Non-IPE & Difference & $\mathrm{df}$ \\
\hline $\begin{array}{l}\text { Mean Probability } \\
\text { Stereotyping }\end{array}$ & for .50 & .80 & $-.30^{* * *}$ & 198 \\
\hline
\end{tabular}

$\mathrm{N}=100$ for each set of teams

*** Significant $(\mathrm{p}<.001)$

The descriptive statistics for IPE teams, as they relate to individual and team mean scores for collaborative behavior, are summarized in Table 2.

Table 2. Descriptives - IPE Teams

\begin{tabular}{|c|c|c|c|c|}
\hline & Min & Max & Mean & SD \\
\hline $\begin{array}{l}\text { Mean Individual Links within } \\
\text { Teams }\end{array}$ & 1.60 & 10.40 & 5.52 & 1.84 \\
\hline Total Links within Teams & 8.00 & 52.00 & 27.60 & 9.18 \\
\hline
\end{tabular}

$\mathrm{N}=100$; over a period of 7 days

The descriptive statistics for Non-IPE teams, as they relate to individual and team mean scores for collaborative behavior, are summarized in Table 3. 
Table 3. Descriptives - Non-IPE Teams

\begin{tabular}{|c|c|c|c|c|}
\hline & Min & $\operatorname{Max}$ & Mean & $\mathrm{SD}$ \\
\hline $\begin{array}{l}\text { Mean Individual Links within } \\
\text { Groups }\end{array}$ & 0.00 & 6.60 & 2.82 & 1.40 \\
\hline Total Links within Groups & 0.00 & 33.00 & 14.11 & 7.01 \\
\hline
\end{tabular}

$\mathrm{N}=100$; over a period of 7 days

The individual and team mean scores for collaborative behavior - as represented by the number of links formed between team members throughout the seven-day period, during which the teams provided care to their patients were significantly higher $(\mathrm{p}<.001)$ in IPE teams, as compared to the Non-IPE teams. The t-test results depicting this significant difference are summarized in Table 4.

Table 4. T-test between IPE and Non-IPE Teams - Collaborative Links

\begin{tabular}{lllll} 
& \multicolumn{1}{c}{ IPE } & Non-IPE & Difference & df \\
\hline $\begin{array}{l}\text { Mean Individual Links } \\
\text { Teams }\end{array}$ & 5.52 & 2.82 & $2.70^{* * *}$ & 198 \\
Total Links within Teams & 27.60 & 14.11 & $13.41^{* * *}$ & 198 \\
\hline
\end{tabular}

$\mathrm{N}=100$ for each set of teams; over a period of 7 days

*** Significant $(\mathrm{p}<.001)$

Additionally, sociograms (Foster, Rapoport, and Orwant, 1963) constructed during the simulation clearly illustrated that a higher degree of collaboration was observed among members of IPE teams, as compared to members of Non-IPE teams - representing a greater potential for shared leadership. Figure 2 illustrates a sample sociogram produced during the simulation for an IPE team, where - on a particular day-every pair in the team, with the exception of the MD and RT, demonstrated collaborative behavior by establishing the illustrated links between one another. Throughout the seven-day simulation period, while the total number of links established in IPE teams was as low as 8 , it was as high as 52 - with the average being 27.60 (see Table 2).

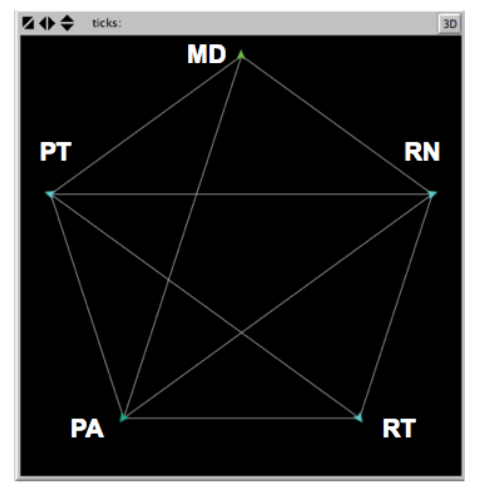

Figure 2. Sample Sociogram for IPE Teams

Figure 3 illustrates a sample sociogram produced during the simulation for a Non-IPE team, where - on a particular day - the only collaborative behavior demonstrated were that between the MD and the PT; that between the MD and the RN'; and that between the PA and the RT. No other links were formed. Throughout the seven-day simulation period, while the total number of links established in Non-IPE teams was as low as 0 (no collaborative behavior whatsoever), it was as high as 33 (see Table 3) - with the average being 14.11. 


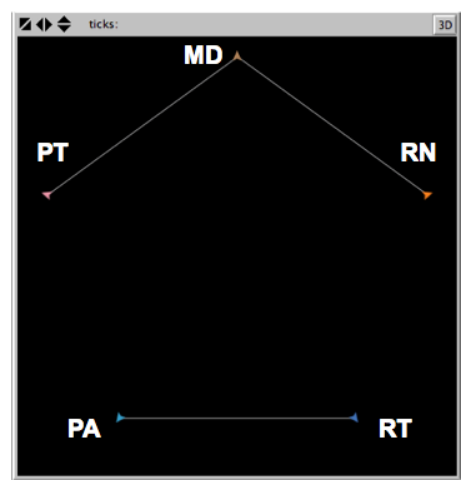

Figure 3. Sample Sociogram for Non-IPE Teams

\section{Discussion}

Being mindful of the limitations of a simulation study, it might be possible to suggest that bringing health care students from different professions together in an interprofessional learning environment could reduce stereotyping and promote the desire for more collaborative behavior, when these students find themselves in clinical settings where they have to work together as part of a health care delivery team. As literature suggests, less stereotyping and greater collaboration in health care delivery teams, in turn, could result in improved outcomes, such as: greater patient satisfaction (Gariola, 1997); higher quality of care (Ducanis and Golin, 1979); more effective clinical treatment (Horbar, Carpenter, Buzas et al., 2004); and more extensive information sharing (Wager, Wickam, Glaser et al., 2005).

The growing interest and investment in IPE have created good momentum in the right direction, even though research on the topic to date is limited and largely confined to clinical settings (Thistlethwaite, 2012). There is a strong call for exploratory research in learning environments (Alvesson and Skoldberg, 2009)to "explore learning, meaning, impact and interprofessionalism in more depth" (Thistlethwaite, 2012, p. 67).Furthermore, in their comprehensive review of IPE literature, where the authors investigated 83 studies that reported IPE activities between 2005 and 2010, Abu-Rish et al. (2012) state that there are many inconsistencies on how IPE activities are conceptualized and implemented - calling for the development and testing of IPE models that can successfully translate effective IPE practices into academic and clinical settings.

The journey that started with the global call to understand and teach how to learn together to work together for health (WHO, 1988) must continue forward at an accelerated pace - especially in academic settings, by complementing core professional curriculum with IPE components - if team-based health care delivery is to live up to its promised potential. As the Assistant Deputy Minister for Health and Education at WHO has stated "we know that interprofessional collaboration is key to providing the best in patient care" and "that means we need to ensure our health and human services students gain the knowledge and skills they need through interprofessional education that begins at the earliest stages of their schooling" (WHO, 2010, p. 36). Removing professional stereotyping which has been identified as one of the "main challenges in international collaborative practice case studies" (WHO, 2010 , p. 62) - is one important step in that direction. .

\section{References}

Abu-Rish, E., Kim, S., Choe, L., Varpio, L., Malik, E., White, A., Craddick, K., Blondon, K., Robins, L., Nagasawa, P., Thigpen, A., Chen, L., Rich, J., \& Zierler, B. (2012). Current trends in interprofessional education of health sciences students; A literature review. Journal of Interprofessional Care, 26(6), 444-451. http://dx.doi.org/10.3109/13561820.2012.715604

Alvesson M. \& Skoldberg K. (2009). Reflexive methodology, $2^{\text {nd }}$ ed. London, UK: Sage Publications.

Barr, H. (2002). Interprofessional education: Today, yesterday and tomorrow. London: Learning and Teaching Support Network: Centre for Health Sciences and Practice.

Centre for the Advancement of Interprofessional Education (2002). Interprofessional education - $A$ definition. London: CAIPE. [Online] Available: http://www.caipe.org.uk/resources/.

Cooke, S., Chew-Graham, C., Boggis, C., \& Wakefield, A. (2001). Organizational stress: A review and critique of theory, research and applications. Los Angeles, CA: Sage Publications.

Cooper, C. L., Dewe, P. J., \& O’Driscoll, M. P. (2003). I never realized that doctors were into feelings too: Changing student perceptions through interprofessional education. Learning in Health and Social Care, 2, 137-146. http://dx.doi.org/10.1046/j.1473-6861.2003.00050.x 
Deffuant, G. (2006). Comparing extremism propagation patterns in continuous opinion models. Journal of Artificial Societies and Social Simulation, 9(3). [Online] Available: http://jasss.soc.surrey.ac.uk/9/3/10.html

Ducanis, A. \& Golin, A. (1979). The interdisciplinary health care team: A handbook. Germantown, MD: Aspen Systems Corporation.

Fernandez, R., Parker, D., Kalus, J., et al. (2007). Using a human patient simulation mannequin to teach interdisciplinary team skills to pharmacy students. American Journal of Pharmaceutical Education. 71(3), 51. http://dx.doi.org/10.5688/aj710351

Foster, C., Rapoport, A., \& Orwant, C. (1963). A study of a large sociogram: Elimination of free parameters. Systems Research and Behavioral Science. 8(1), 56-65.

Gariola, G. (1997). Developing rural interdisciplinary geriatrics teams in a changing health care environment. Journal of Allied Health, 26(1), 27-29.

Gilbert, N. (2008). Agent-based Models. Los Angeles, CA: Sage Publications.

Gilbert, N., den Besten, M., Bontovics, A., Craenen, B., Dvina, F., Eiben, A., et al. (2006). Emergingartificialsocietiesthroughlearning. Journal of Artificial Societies and Social Simulation, 9(2). [Online] Available: http://jasss.soc.surrey.ac.uk/9/2/9.html

Gilbert, N., Pyka, A., \& Ahrweiler, P. (2001). Innovation networks : A simulation apporach. Journal of Artificial Societies and Social Simulation, 4(3). [Online] Available: http://jasss.soc.surrey.ac.uk/4/3/8.html

Horbar, J. D, Carpenter, J., Buzas, J. et al. (2004). Collaborative quality improvement to promote evidence based surfactant for preterm infants: a cluster randomisedtrial.BMJ (Clinical research ed.).329(7473), 1004. http://dx.doi.org/10.1136/bmj.329.7473.1004

Howell, D. (2009). Occupational therapy students in the process of interprofessional collaborative learning: A grounded theory study. Journal of Interprofessional Care, 23(1), 67-80. http://dx.doi.org/10.1080/13561820802413281

Jacobsen, F. \& Lindqvist, S. (2009). A two-week stay in an interprofessional training unit changes students' attitudes to health professionals. Journal of Interprofessional Care, 23(3), 242-250. http://dx.doi.org/10.1080/13561820902739858

Jansen, M \& Jager, W. (1999). An integrated approach to simulating behavioural processes: A case study of the lock-in of consumption patterns. Journal of Artificial Societies and Social Simulation, 2(2). [Online] Available: http://jasss.soc.surrey.ac.uk/2/2/2.html

Lewitt, M., Ehrenborg, E., Scheja, M., \& Brauner, A. (2010). Stereotyping at the undergraduate level revealed during interprofessional learning between future doctors and biomedical scientists. Journal of Interprofessional Care, 24(1), 53-62. http://dx.doi.org/10.3109/13561820902921704

Mehra, A., Smith, B., Dixon, A., \& Robertson, B. (2006). Distributed leadership in teams: The network of leadership perceptions and team performance. The Leadership Quarterly. 17(3), 232-245. http://dx.doi.org/10.1016/j.leaqua.2006.02.003

Ruebling, I., Lavin, A. et al. (2000). Facilitating factors for, barriers to, and outcomes of interdisciplinary education projects in the health sciences. Journal of Allied Health. 29(3): 165-70.

Sargeant, J. (2012). Theories to aid understanding and implementation of interprofessional education. Journal of Continuing Education in the Health Professions, 29(3), 178-184. http://dx.doi.org/10.1002/chp.20033

Schelling, T. (1971). Dynamic models of segregation. Journal of Mathematical Sociology, 1, 143-186. http://dx.doi.org/10.1080/0022250X.1971.9989794

Thistlethwaite, J. (2012). Interprofessional education: A review of context, learning and the research agenda. Medical Education, 46(1), 58-70. http://dx.doi.org/10.1111/j.1365-2923.2011.04143.x

Thistlethwaite, J. \& Moran, M. (2010). Learning outcomes for interprofessional education: Literature review and synthesis. Journal of Interprofessional Care, 24(5), 503-513. http://dx.doi.org/10.3109/13561820.2010.483366

Wager, K., Wickham, F., \& Glaser, J. (2005). Health care information systems: A practical approach for health care management, 2nd Edition. Hoboken, NJ: Jossey-Bass / Wiley.

World Health Organization. (1988). Learning together to work together for health. Geneva: WHO.

World Health Organization. (2010). Framework for action on interprofessional education and collaborative practice. Geneva: WHO.

Wilensky, U. (1999). NetLogo. http://ccl.northwestern.edu/netlogo/. Center for Connected Learning and Computer-Based Modeling, Northwestern University. Evanston, IL. 